\title{
Ventilator Associated Pneumonia: Continuous Versus Intermittent Administration of Piperacillin- tazobactam in Intensive Care Unit of CCMMC
}

\section{Hospital}

\author{
Dr. Mahendra M. Sawarkar ${ }^{1}$, Dr. Shushrut Mahendra Sawarkar ${ }^{* 2}$ \\ Associate Professor Department of Medicine CCMM Medical College Durg, CG \\ SR NKP Salve Institute of Medical Sciences, Higna Nagpur
}

Address for Correspondence

Dr. Shushrut Mahendra Sawarkar

SR NKP Salve institute of Medical sciences, Higna Nagpur

\begin{abstract}
Introduction: Ventilator-associated pneumonia (VAP) can be defined as pneumonia occuring 48-72 hours or thereafter following endotracheal intubation, it is characterized by the presence of a new or progressive infiltrate, signs of systemic infection like fever, altered white blood cell count, changes in sputum characteristics. Duration of mechanical ventilation determines the type of organism that causes VAP. Early VAP is caused by pathogens that are sensitive to most of the antibiotics, whereas late onset VAP may be caused by multi-drug resistant bacteria. There is no gold standard diagnostic criterion for VAP. Many clinical methods have been recommended but there is no sensitivity or specificity to identify this disease. In this study we tried to compare the clinical outcomes of continuous and intermittent administration of Piperacillintazobactam. Material and Methods: For diagnosis of VAP following criteria were considered: white blood cell count more than 10,000 cells/mm 3 or less than 4000 cells $/ \mathrm{mm} 3$; new onset of purulent sputum or a change in sputum character; body temperature $>38^{\circ} \mathrm{C}$ or $\left\langle 35.5^{\circ}\right.$; chest $\mathrm{X}$ ray showing new or progressive infiltrate and a significant quantitative pathogen culture from respiratory secretions (tracheal aspirate $>106$ colonyforming units $/ \mathrm{ml}$ or growth of $\geq 104$ colony-forming units $/ \mathrm{mL}$ of microorganism on bronchoscopic bronchoalveolar lavage (BAL) culture or isolation of the same microorganism in blood and respiratory secretions on third day and eighth day. APACHE II score were recorded on admission and CPIS was measured at the onset of VAP symptoms and at third and eighth day. Demographic and other variable of the patients were recorded. Results: 50 patients were included in the study of which 25 were placed in continuous Infusion (CI) group and 25 in intermittent infusion (II) group. APACHE II score on admission in CI and II was 19. $9 \pm 4.9$ and $21.4 \pm 5.6$ respectively. Duration of mechanical ventilation in CI group was $39.1 \pm 20.5$ days. Total number of antibiotics administered in CI group was $5.5 \pm 2.0$ and II group was $5 \pm 1.5$. Duration of piperacillin - tazobactum treatment was $21 \pm 11.6$ (days) in CI group and $19 \pm 9.6$ in II group. Mortality rate observed in CI was 8 (32\%) and in II was 9 (36\%). No significant difference was observed in CPIS scores of both the group in Day 1, day 3 and day 8. Conclusion: There is significant morbidity in critically ill patients with VAP and there is lack of gold standard criteria for diagnosis. No significant difference was observed in CI and II group in term of clinical outcome.
\end{abstract}

\section{Introduction}

Mechanical ventilation (MV) is a widely used intervention for critically ill patients in intensive care units (ICUs). ${ }^{[1]}$ Ventilatorassociated pneumonia (VAP) can be defined as pneumonia occuring 48-72 hours or thereafter following endotracheal intubation, it is characterized by the presence of a new or progressive infiltrate, signs of systemic infection like fever, altered white blood cell count, changes in sputum characteristics. ${ }^{[2]}$ About half of all cases of hospital-acquired pneumonia can be ventilatorassociated pneumonia. ${ }^{[3]}$ It is the second most common nosocomial infection in the intensive care units (ICU) and the most common in mechanically ventilated patients. Early onset VAP is defined as pneumonia that occurs within 4 days and late onset VAP emerges after 4 days of intubation. The complex interaction between the endotracheal tube, presence of risk factors, high risk patients, virulence of the invading bacteria and host immunity determine the development of VAP. ${ }^{[5]}$ Direct access to the lower respiratory tract by microorganisms can be acquired by micro aspiration, development of a biofilm within the endotracheal tube and impairment of mucociliary clearance of secretions. ${ }^{[6]}$

Duration of mechanical ventilation determines the type of organism that causes VAP. Early VAP is caused by pathogens that are sensitive to most of the antibiotics, whereas late onset VAP may be caused by multi-drug resistant bacteria. ${ }^{[7]}$

Approximately $50 \%$ of all antibiotics given in ICUs are for treatment of VAP ${ }^{[8]}$ There is no gold standard diagnostic criterion 


\section{International Journal of Innovative Research in Medical Science (IJIRMS) Volume 03 Issue 12 Dec 2018, ISSN: 2455-8737, Imp. Factor - 4.102 Available online at - www.ijirms.in}

for VAP. Many clinical methods have been recommended but there is no sensitivity or specificity to identify this disease. ${ }^{[9]}$ Clinical diagnosis of VAP can also miss about a third of VAPs in the ICU. ${ }^{[10]}$ Owing to the high rate of resistance to monotherapy combination therapy is always recommended. ${ }^{[11]}$ Although multi drug resistant (MDR) organisms are usually associated with lateonset VAP, studies suggests that they are increasingly associated with early-onset VAP as well. ${ }^{[12]}$ Piperacillin-tazobactam which is a broad-spectrum $\beta$-lactam- $\beta$-lactamase inhibitor antibiotic can be used for the treatment of critically ill patients with $\mathrm{VAP}^{[2]}$ The routine mode of piperacillin injection is intermittent infusion (II) but continuous infusion (CI) can also be advocated for improving the time above the MIC (minimum inhibitory concentration). But the clinical benefit of CI or II of $\beta$-lactam antibiotics is doubtful and clinical outcomes such as mortality, leucocytosis, pyrexia, microbiological outcome and length of stay are comparable between bolus and continuous dosing of $\beta$-lactam antibiotics in seriously ill patients. ${ }^{[13,14,15]}$

In this study we tried to compare the clinical outcomes of continuous and intermittent administration of Piperacillintazobactam by serial measurements of the Clinical Pulmonary Infection Score (CPIS).

\section{Material and Methods}

Present study was carried out at CCM Medical College in the department of Medicine. In this prospective study we included 57 patients which were critically ill and were incubated and fulfilled the criteria for VAP. For diagnosis of VAP following criteria were considered: white blood cell count more than 10,000 cells $/ \mathrm{mm}^{3}$ or less than 4000 cells $/ \mathrm{mm}^{3}$; new onset of purulent sputum or a change in sputum character; body temperature $>38^{\circ} \mathrm{C}$ or $<35.5^{\circ}$; chest $\mathrm{X}$ ray showing new or progressive infiltrate and a significant quantitative pathogen culture from respiratory secretions (tracheal aspirate $>106$ colony-forming units $/ \mathrm{mL}$ or growth of $\geq 104$ colonyforming units $/ \mathrm{mL}$ of microorganism on bronchoscopic bronchoalveolar lavage (BAL) culture or isolation of the same microorganism in blood and respiratory secretions on third day and eighth day. All patients on ventilator were more than 48 hours. Patients excluded were: HIV / acquired immunodeficiency syndrome AIDS positive, hypersensitive to Piperacillintazobactam, suffering from kidney failure. 50 patients were eligible and were included in the study and remain alive after 8 days of intubation. Acute Physiology and Chronic Health Evaluation II (APACHE II) score was primarily used to predict the mortality of the patients. ${ }^{[16]}$ APACHE II score were recorded on admission and CPIS was measured at the onset of VAP symptoms and at third and eighth day. Demographic and other variable of the patients were recorded. Written informed consent was obtained from the concerned relatives of the patients.

Statistical analysis was performed using SPSS software. All data was entered in the Microsoft Excel 2010 edition. Variables were stated as mean and standard deviation. Chi-square test or Fisher's exact test was applied wherever necessary and P-values $<0.05$ were considered significant.

\section{Results and Observation}

50 patients had fulfilled the criteria of the study and were grouped in continuous Infusion (CI) group and intermittent infusion (II) group in each of the group there were 25 patients

Table 1: Characteristics if the patients

\begin{tabular}{|c|c|c|c|c|}
\hline Variable & CI $(\mathbf{n}=25)$ & II $(\mathbf{n}=25)$ & $P$ value & Significance \\
\hline Age & $51.6 \pm 16.7$ & $54.7 \pm 13.4$ & $\mathrm{P}=0.4726$ & Not significant \\
\hline Male & $14(56 \%)$ & $13(52 \%)$ & & \\
\hline Female & $11(44 \%)$ & $12(48 \%)$ & & \\
\hline APCHE II on admission & $19.9 \pm 4.9$ & $21.4 \pm 5.6$ & $\mathrm{P}=0.3185$ & Not significant \\
\hline Duration of mechanical ventilation & $39.1 \pm 20.5$ & $44.2 \pm 22.4$ & $\mathrm{P}=0.4052$ & Not significant \\
\hline Number of antibiotics & $5.5 \pm 2.0$ & $5 \pm 1.5$ & $\mathrm{P}=0.3223$ & Not significant \\
\hline Duration of Piperacillin - tazobactum (days) & $21 \pm 11.6$ & $19 \pm 9.6$ & $\mathrm{P}=0.5098$ & Not significant \\
\hline Mortality rate & $8(32 \%)$ & $9(36 \%)$ & $\mathrm{P}=0.7676$ & Not significant \\
\hline Days of Hospital stay & $49 \pm 16.6$ & $53 \pm 21.6$ & $\mathrm{P}=0.4664$ & Not significant \\
\hline
\end{tabular}

CI: continuous Infusion, II: Intermittent Infusion :( mean \pm SD): SD Standard Deviation

Mean age in CI group was $51.6 \pm 16.7$ (mean \pm SD) and in II group was $54.7 \pm 13.4 \mathrm{P}$ value 0.4726 . In CI group total male were 14 $(56 \%)$ and female were $11(44 \%)$ while in II group total male were $13(52 \%)$ and female were $12(48 \%)$. Slight preponderance towards male was seen in both the group. APACHE II score on admission in CI and II was $19.9 \pm 4.9$ and $21.4 \pm 5.6$ respectively. Duration of mechanical ventilation in CI group was $39.1 \pm 20.5$ days. Total number of antibiotics administered in CI group was $5.5 \pm 2.0$ and II group was $5 \pm 1.5$. Duration of piperacillin - tazobactum treatment was $21 \pm 11.6$ (days) in CI group and $19 \pm 9.6$ in II group. Mortality rate observed in CI was 8 (32\%) and in II were $9(36 \%)$. Number of days in hospital stay was $49 \pm 16.6$ and $53 \pm 21.6$ in CI and II group respectively.
Table 2: Mean CPIS score

\begin{tabular}{|c|c|c|c|}
\hline CPIS score & $\mathrm{CI}(\mathrm{n}=25)$ & $\mathrm{II}(\mathrm{n}=25)$ & $\mathrm{P}$ value \\
\hline Day 1 & $6.96 \pm 0.96$ & $6.85 \pm 1.71$ & $\mathrm{P}=0.7803, \mathrm{NS}$ \\
\hline Day 3 & $8.21 \pm 1.23$ & $8.45 \pm 1.45$ & $\mathrm{P}=0.5310, \mathrm{NS}$ \\
\hline Day 8 & $8.07 \pm 1.99$ & $7.96 \pm 1.85$ & $\mathrm{P}=0.8404, \mathrm{NS}$ \\
\hline
\end{tabular}

NS Not Significant

On Day 1 CPIS scores in CI was $6.96 \pm 0.96$ and in II was $6.85 \pm$ 1.71. Day 3 CPIS score in CI and II was $8.21 \pm 1.23$ and $8.45 \pm$ 1.45 respectively. On day 8 CPIS scores in CI was $8.07 \pm 1.99$ and in II was $7.96 \pm 1.85$. No significant difference was observed in CPIS scores of both the group in Day 1, day 3 and day 8 . 


\section{International Journal of Innovative Research in Medical Science (IJIRMS) Volume 03 Issue 12 Dec 2018, ISSN: 2455-8737, Imp. Factor - 4.102 \\ Available online at - www.ijirms.in}

\section{Discussion}

In a study it was suggested that non-invasive sampling with semi quantitative cultures to diagnose VAP should be done rather than invasive sampling with quantitative cultures and rather than noninvasive sampling with quantitative cultures also it is recommended that rather than using serum PCT plus clinical criteriatoinitiate antibiotic therapy clinical criteria alone can be used. It is recommended that all hospitals should regularly generate and disseminate a local antibiogram, ideally one that is specific to their intensive care population so that empirical treatment should be started. ${ }^{[17]}$ Selection of appropriate antibiotic depends on the duration of mechanical ventilation. Late onset VAP (> 4 days) requires broad spectrum antibiotics whereas early onset ( $\leq 4$ days) can be treated with limited spectrum antibiotics and delay in initiation of antibiotic treatment may increase mortality risk with $\mathrm{VAP}^{[2]}$

The standard mode of giving piperacillin is II to reduce toxicity but $\mathrm{CI}$ is of particular importance for optimizing the time above the MIC. ${ }^{[18]}$

In our study no significant difference was noted in CI and II group in terms of clinical outcomes, severity of illness, mortality, duration of mechanical ventilation, clinical cure from actual infection, time to normalization of leucocytosis or pyrexia and lengths of ICU stay. Although mortality was slight less in CI group but was not statistically significant. Similar results were shown by other studies by Angus BJ et al., ${ }^{[19]}$ Pédeboscq C et al., ${ }^{[20]}$ and Nicolau $\mathrm{DP}^{[21]}$ et al. Duration of piperacillin-tazobactam regimen was correlated with the CPIS score at the onset of VAP symptoms. In our study in CPIS scores of day 1 , day3, and day 8 no statistically significant difference was observed. In a study by Luna $\mathrm{CM}$ et al., ${ }^{[22]}$ of prospective evaluation of the clinical pulmonary infection score as an early clinical predictor of outcome similar results were observed.

In our study isolation of high risk organisms like Acinetobacter, Pseudomonas in VAP patients was low this may be the reason that our mortality was slightly low as compared to other study by Kollef et al., ${ }^{[23]}$ in which Pseudomonas aeruginosa and Acinetobacter sp were detected as the most common MDR pathogens. The limitation in our study was sample size was small as well as randomization was not done in two group.

\section{Conclusion}

VAP occurs frequently and is associated with significant morbidity in critically ill patients. VAP continues to be an inconspicuous clinical syndrome as there is lack of gold standard criteria for diagnosis. No significant difference was observed in CI and II group in term of clinical outcome. Before choosing the standard mode of administering $\beta$-lactams more studies are required.

\section{References}

[1] Vincent JL, Rello J, Marshall J, Silva E, Anzueto A, Martin CD, Moreno R, Lipman J, Gomersall C, Sakr Y, Reinhart K, Investigators EIGo International study of the prevalence and outcomes of infection in intensive care units.

JAMA.

2009;302:2323-9.

doi:

10.1001/jama.2009.1754.

[2] American Thoracic Society. Infectious Diseases Society of America. Guidelines for the management of adults with hospital-acquired, ventilator-associated, and healthcare-associated pneumonia.Am J RespirCrit Care Med. 2005 Feb 15; 171(4):388-416.

[3] Vincent JL, Bihari DJ, Suter PM, Bruining HA, White J, Nicolas-Chanoin MH, Wolff M, Spencer RC, Hemmer $\mathrm{M}$. The prevalence of nosocomial infection in intensive care units in Europe. Results of the European Prevalence of Infection in Intensive Care (EPIC) Study. EPIC International Advisory Committee.JAMA. 1995 Aug 2330; 274(8):639-44.

[4] Hunter JD. Ventilator associated pneumonia.BMJ. 2012 May 29; 344():e3325.

[5] Zolfaghari PS, Wyncoll DL. The tracheal tube: gateway to ventilator-associated pneumonia.Crit Care. 2011; 15(5):310.

[6] Mietto C, Pinciroli R, Patel N, Berra L.Ventilator associated pneumonia: evolving definitions and preventive strategies.Respir Care. 2013 Jun; 58(6):9901007.

[7] Kalanuria AA, Ziai W, Mirski M. Ventilator-associated pneumonia in the ICU. Crit Care. 2014;18(2):208. Published 2014 Mar 18. doi:10.1186/cc13775

[8] Vincent JL, Bihari DJ, Suter PM, Bruining HA, White J, Nicolas-Chanoin MH, Wolff M, Spencer RC, Hemmer $\mathrm{M}$. The prevalence of nosocomial infection in intensive care units in Europe. Results of the European Prevalence of Infection in Intensive Care (EPIC) Study. EPIC International Advisory Committee.JAMA. 1995 Aug 2330; 274(8):639-44.

[9] National Healthcare Safety Network (NHSN) July 2013 CDC/NHSN Protocol Clarifications. 2013. http://www.cdc.gov/nhsn/PDFs/pscManual/10VAE_FINAL.pdf

[10] Cook DJ, Walter SD, Cook RJ, Griffith LE, Guyatt GH, Leasa D, Jaeschke RZ, Brun-Buisson C. Incidence of and risk factors for ventilator-associated pneumonia in critically ill patients.Ann Intern Med. 1998 Sep 15; 129(6):433-40.

[11] Munoz-Price LS, Weinstein RA. Acinetobacter infection.N Engl J Med. 2008 Mar 20; 358(12):1271-81.

[12] Martin-Loeches I, Deja M, Koulenti D, Dimopoulos G, Marsh B, Torres A, Niederman MS, Rello J, EU-VAP Study Investigators.Potentially resistant microorganisms in intubated patients with hospital-acquired pneumonia: the interaction of ecology, shock and risk factors.Intensive Care Med. 2013 Apr; 39(4):672-81.

[13] McNabb JJ, Nightingale CH, Quintiliani R, Nicolau DP. Cost-effectiveness of ceftazidime by continuous infusion versus intermittent infusion for nosocomial pneumonia. Pharmacotherapy 2001;21:549-55.

[14] Sakka SG, Glauner AK, Bulitta JB, Kinzig-Schippers M, Pfister W, Drusano GL, et al. Population pharmacokinetics and pharmacodynamics of continuous versus short-term infusion of imipenem-cilastatin in critically ill patients in a randomized, controlled trial. Antimicrob Agents Chemother 2007;51:3304-10 
[15] Roberts JA, Boots R, Rickard CM, Thomas P, Quinn J, Roberts DM, et al. Is continuous infusion ceftriaxone better than once-a-day dosing in intensive care? J Antimicrob Chemother 2007;59:285-91

[16] Knaus WA, Draper EA, Wagner DP, Zimmerman JE. APACHE II: A severity of disease classification system. Crit Care Med 1985;13:818-29.

[17] Kalil, Andre C et al. "Management of Adults With Hospital-acquired and Ventilator-associated Pneumonia: 2016 Clinical Practice Guidelines by the Infectious Diseases Society of America and the American Thoracic Society"Clinical infectious diseases: an official publication of the Infectious Diseases Society of America vol. 63,5 (2016): e61-e111.

[18] Turnidge JD. The pharmacodynamics of beta-lactams. Clin Infect Dis 1998; 27:10-22.

[19] Angus BJ, Smith MD, Suputtamongkol Y, Mattie H, Walsh AL, Wuthiekanun V, et al. Pharmacokineticpharmacodynamic evaluation of ceftazidime continuous infusion vs intermittent bolus injection in septicaemicmelioidosis. $\mathrm{Br} \quad \mathrm{J}$ ClinPharmacol 2000; 50:184-91.

[20] Pédeboscq S, Dubau B, Frappier S, Hernandez V, Veyssières D, Winnock $S$, et al. [Comparison of 2 administration protocols (continuous or discontinuous) of a time-dependent antibiotic, Tazocin]. PatholBiol (Paris) 2001;49:540-7

[21] Nicolau DP, McNabb J, Lacy MK, Quintiliani R, Nightingale $\mathrm{CH}$. Continuous versus intermittent administration of ceftazidime in intensive care unit patients with nosocomial pneumonia. Int $\mathbf{J}$ Antimicrob Agents 2001; 17:497-504.

[22] Luna CM, Blanzaco D, Niederman MS, Matarucco W, Baredes NC, Desmery P, et al. Resolution of ventilatorassociated pneumonia: Prospective evaluation of the clinical pulmonary infection score as an early clinical predictor of outcome. Crit Care Med 2003; 31:676-82.

[23] Kollef MH, Silver P, Murphy DM, Trovillion E. The effect of late-onset ventilator-associated pneumonia in determining patient mortality. Chest 1995; 108: 1655-62. 